\title{
ANESTESIA BALANCEADA EM LAGARTO-TEIÚ (Tupinambis merianae): RELATO DE CASO
}

\author{
Erica Cristina Bueno do Prado Guirro, ${ }^{1}$ Olicies da Cunha,,${ }^{1}$ Ana Paula Santos, ${ }^{2}$ \\ Lilian TofFanetto $^{2}$ e Nei Moreira ${ }^{1}$ \\ 1. Docente do Curso de Medicina Veterinária UFPR, Campus Palotina. E-mail: ericaguirro@ufpr.br \\ 2. Aluna do Curso de Medicina Veterinária UFPR, Campus Palotina.
}

RESUMO

Um lagarto-teiú (Tupinambis merianae) submetido à osteossíntese de úmero recebeu midazolam $(0.073 \mathrm{mg} / \mathrm{kg}, \mathrm{i} . \mathrm{m}$.) e morfina $(0.224 \mathrm{mg} / \mathrm{kg}$, i.m.) na medicação pré-anestésica, foi induzido com cetamina ( $30 \mathrm{mg} / \mathrm{kg}$, i.m.) e teve manutenção anes- tésica com isofluorano diluído em $\mathrm{O}_{2}(1 \mathrm{~L} / \mathrm{Kg} / \mathrm{min})$ fornecido por máscara facial, além de bloqueio anestésico local circular com $5 \mathrm{mg} / \mathrm{kg}$ lidocaína $2 \%$ sem vasoconstritor. O protocolo anestésico empregado mostrou-se eficiente e seguro ao paciente.

PALAVRAS-CHAVES: Anestesia, lagarto-teiú, Tupinambis merianae.

ABSTRACT

\section{MULTIMODAL ANESTHESIA IN TEGU LIZARD Tupinambis merianae: CASE REPORT}

A tegu lizard Tupinambis merianae submitted to osteosynthesis on umero received midazolam $(0.073 \mathrm{mg} / \mathrm{kg}$, i.m. ) and morphine $(0.224 \mathrm{mg} / \mathrm{kg}$, i.m. $)$ in pre-medication. The animal was induced by ketamine $(30 \mathrm{mg} / \mathrm{kg}$, i.m. ) and anesthesia was maintai-

KEYWORDS: Anesthesia, reptile, Tupiambis merianae.

\section{INTRODUÇÃO}

Como os répteis são ectotérmicos, alterações na temperatura influenciam a distribuição, o metabolismo e a excreção de fármacos (HERNADEZ-DIVERS, 2002). Ainda há carência de informações quanto aos fármacos, doses e técnicas anestésicas que garantam segurança e analgesia aos répteis. Para contornar essa dificuldade, propõe-se a extrapolação alométrica, que permite o cálculo de doses requeridas por diferentes espécies animais. Para tanto, é necessário conhecer o peso metabólico do animal, que depende da massa corporal $(\mathrm{kg})$ e da constante de energia $(\mathrm{K})$, sendo ned with isofluorane diluted in $\mathrm{O}_{2}(1 \mathrm{~L} / \mathrm{Kg} / \mathrm{min})$ and supplied by facial mask, besides local anesthesia with lidocaine $2 \%$ without adrenaline $(5 \mathrm{mg} / \mathrm{kg})$. This anesthesia protocol was efficient and safe to patient.

10 para répteis e 70 para mamíferos placentários (SEDGWICK, 2001; ABOU-MADI, 2006).

Embora MUIR et al. (2001) tenham relatado como desnecessária a administração de pré-medicação na anestesia de répteis, SEDGWICK (2001) sugere a utilização de agonistas $\alpha_{2}$, benzodiazepínicos ou anticolinérgicos. Ambos citam a cetamina como agente indutor adequado e apontam o isofluorano como agente inalatório de escolha para répteis, fornecido por tubo orotraqueal ou máscara. A frequência respiratória deve ser monitorada e é preciso mantê-la acima de $3 \mathrm{mpm}$ para evitar riscos no período transoperatório (MUIR et al., 2001; SEDGWICK, 2001). 


\section{RELATO DO CASO}

Um jovem lagarto-teiú (Tupinambis merianae) de $1,4 \mathrm{~kg}$ foi atendido no Hospital Veterinário da UFPR, Campus Palotina, com sinais de atropelamento. Verificaram-se trauma e impotência funcional do membro torácico esquerdo acompanhados por edema e dor na região de úmero.

Durante o exame radiográfico, utilizou-se cetamina (30mg $/ \mathrm{kg}$, i.m.) para posicionar adequadamente o animal e diagnosticou-se fratura fechada, completa e transversa na diáfise do úmero esquerdo. Instituiuse tratamento clínico baseado em repouso, terapia antinflamatória com cetoprofeno. Após quatro dias, o animal foi submetido à osteossíntese.

Optou-se por neroleptoanalgesia, com associação de midazolam $(0,073 \mathrm{mg} / \mathrm{kg}$, i.m. $)$ e morfina $(0,224 \mathrm{mg} / \mathrm{kg}$, i.m. $)$, sendo a dose do opioide calculada por extrapolação alométrica. Após vinte minutos, administrou-se cetamina ( $30 \mathrm{mg} / \mathrm{kg}$, i.m. $)$, e o paciente foi encaminhado ao centro cirúrgico. Para redução do metabolismo do lagarto, o ar-condicionado foi mantido ligado e não se utilizou colchão térmico. Realizou-se a manutenção anestésica com isofluorano, através de máscara facial (Figura 1A) parcialmente vedada com uma luva de procedimento fixada à cabeça do animal com esparadrapo (Figura 1B). Durante todo o procedimento, manteve-se o fluxo de oxigênio em $1 \mathrm{~L} / \mathrm{kg} /$ minuto e monitorou-se a frequência respiratória.

O lagarto foi posicionado em decúbito lateral direito com auxílio de compressas (Figura 1C). Realizouse bloqueio anestésico local circular na região proximal do úmero com $5 \mathrm{mg} / \mathrm{kg}$ lidocaína $2 \%$ sem vasoconstritor, diluída em $\mathrm{NaCl} 0,9 \%$ até completar o volume de $1 \mathrm{~mL}$, que foi dividido entre o espaço subcutâneo e a musculatura. Enquanto aguardavam-se dez minutos para o início da cirurgia, procedeu-se à antissepsia com $\mathrm{NaCl}$ 0,9\%, iodopovidine e álcool iodado.

Durante toda a cirurgia, a frequência respiratória manteve-se acima de $4 \mathrm{mpm}$. Cerca de 45 minutos após a indução anestésica, foi necessário reaplicar $50 \%$ da dose inicial de cetamina. A duração do procedimento cirúrgico foi de 95 minutos, com um consumo total de isofluorano de $22 \mathrm{~mL}$.
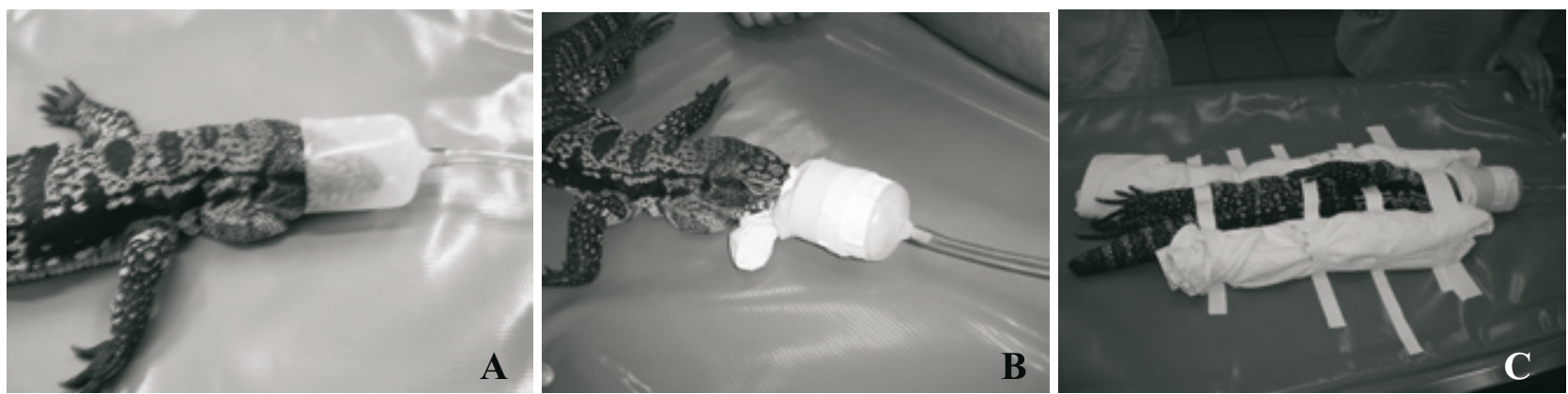

FIGURA 1. Lagarto-teiú (Tupinambis merianae) sob anestesia. A) Uso de máscara facial para fornecimento de isofluorano. B) Máscara facial parcialmente vedada com esparadrapo. C) Lagarto colocado em decúbito lateral direito por meio de compressas e esparadrapo.

\section{RESULTADOS E DISCUSSÃO}

O emprego de neuroleptoanalgesia na prémedicação mostrou-se adequado, apesar de MUIR III et al. (2001) considerarem desnecessário o uso de prémedicação em répteis. A associação entre midazolam e morfina promoveu tranquilização, hipnose, relaxamento muscular e analgesia, permitindo a manipulação no membro e relaxamento muscular, pois o lagarto se encontrava menos reativo à estimulação. Quanto às doses empregadas, utilizou-se $0,073 \mathrm{mg} / \mathrm{kg}$ do benzodiazepínico, conforme preconizado por SEDGWICK (2001). Por extrapolação alométrica, calculou-se a dose de morfina $(0,224 \mathrm{mg} / \mathrm{kg}$, i.m.), sem se verificar prejuízo ao paciente. Dado o uso intramuscular desses fármacos, aguardar vinte minutos entre a aplicação da pré-medicação e a indução do paciente mostrou-se uma medida importante.

O emprego de $30 \mathrm{mg} / \mathrm{kg}$ cetamina promoveu indução cinco minutos após sua administração e foi con- 
siderada segura, corroborando o afirmado por MUIR III et al. (2001) e SEDGWICK (2001). A ausência do reflexo postural prolongou-se por 45 minutos, quando foi necessário reaplicar metade da dose inicialmente empregada. A utilização da via intramuscular foi satisfatória e, em répteis, essa forma de administração é considerada a principal e mais utilizada (SCHUMACKER, 1996).

A colocação de máscara facial e o uso da luva de procedimento fixada por esparadrapo à cabeça do animal reduziram, parcialmente, o escape do isofluorano. Conforme já foi relatado previamente (SKOVGAARD et al., 2005), o isofluorano foi seguro e, mantido o fluxo de oxigênio em $1 \mathrm{~L} / \mathrm{kg} /$ min sugerido por MUIR et al. (2001), não houve emergência anestésica e a frequência respiratória manteve-se acima do nível crítico para a espécie, que é de 3mpm (MUIR et al., 2001; SEDGWICK, 2001). Em virtude do posicionamento do paciente, não foi possível realizar a auscultação cardíaca durante o ato cirúrgico, apesar de sua aferição ser considerada importante.

Como a pele de répteis é extremamente sensível à estimulação dolorosa (SEDGWICK, 2001), a realização do bloqueio anestésico com lidocaína $2 \%$ sem vasoconstritor foi benéfica e, possivelmente, reduziu o volume de isofluorando consumido e diminuiu a necessidade de outras reaplicações do agente dissociativo. Não se verificaram sinais de intoxicação e, portanto, a dose de $5 \mathrm{mg} / \mathrm{kg}$ de lidocaína não deve ser tóxica para a espécie, como relatado por ANDRADE et al. (2004), que utilizaram doses superiores e não constataram problemas. A diluição do anestésico local em $\mathrm{NaCl} 0,9 \%$ foi eficiente para realização do bloqueio circular.

A duração da recuperação anestésica foi de cerca de doze horas. Esse período é significativamente menor que o relatado por MUIR III et al. (2001). Esses autores citam que a associação entre anestésicos gerais intravenosos e isofluorano prolonga para mais de 24 horas a recuperação anestésica de répteis.

\section{CONCLUSÕES}

O protocolo anestésico baseado na pré-medicação com midazolam e morfina, indução com cetamina e manutenção com isofluorano, além de anestesia local com lidocaína, foi eficiente e seguro no emprego em lagarto-teiú submetido à cirurgia ortopédica em membro torácico.

\section{REFERÊNCIAS}

ABOU-MADI, N. Anesthesia and analgesia of small mammals. In: GLEED, R. D.; LUDDERS, J. W. Recent advances in veterinary anesthesia and analgesia: companion animals. Ithaca: International Veterinary Information Service, 2006. Disponível em: $<$ http:// www.ivis.org.> Acesso em: 10 jan. 2008.

ANDRADE, D. V.; BRITO, S. P.; TOLEDO, L. F.; ABE, A. S. Seasonal changes in blood oxygen transport and acid-base status in the tegu lizard, Tupinambis merianae. Respiratory Physiology \& Neurobiology, v. 140, p. 197-208, 2004.

HERNANDEZ-DIVERS, S. J. Therapeutic techniques of reptiles. In: World Small Animal Veterinary Association Congress. Granada: International Veterinary Information Service, 2006. Disponível em: <http://www.ivis.org.> Acesso em: 11 jan. 2008.

MUIR III, W. W.; HUBBELL, J. A. E.; SKARDA, R. T.; BEDNARSKI, R. M. Procedimentos anestésicos em animais de estimação exóticos. In.: Manual de anestesia veterinária. São Paulo: Artmed, 2001. p. 297-323.

SCHUMACKER, J. Reptiles and amphibians. In.: THURMON, J. C.; TRANQUILLI, W. J.; BENSON, G. J. Lumb \& Jones' veterinary anesthesia. 3 . ed. Baltimore: Williams and Wikins, 1996. p. 670-685.

SEDGWICK, C. J. Anestesia para mamíferos exóticos de pequeno a médio porte, pássaro e répteis. In.: PADDLEFORD, R. R. Manual de anestesia de pequenos animais. São Paulo: Roca, 2001. p. 365-407.

SKOVGAARD, N.; ABE, A. S.; ANDRADE, D. V.; WANG, T. Hypoxic pulmonary vasoconstriction in reptiles: a comparative study of four species with different lung structures and pulmonary blood pressures. American Journal of Physiology and Regulatory Integrative Comparative Physiology, n. 289, p. 1280-1288, 2005. 